Original Article

\title{
Effectiveness of academic stress management programme on academic stress and academic performance among higher secondary students in selected schools of Udupi District
}

\author{
Nikitha $S^{1}$, Tessy Treesa Jose ${ }^{2} \&$ Blessy Prabha Valsaraj ${ }^{3}$ \\ ${ }^{1}$ Postgraduate, ${ }^{2}$ Professor \& HOD, Psychiatric/M ental Health Nursing, ${ }^{3}$ Associate Professor, Department of Psychiatric \\ Nursing, M anipal College of Nursing Manipal, Manipal University, M anipal, Udupi, Karnataka - 576104. \\ Correspondence \\ Tessy Treesa Jose \\ Professor \& HOD, Psychiatric/M ental Health Nursing, Manipal College of Nursing M anipal, \\ Manipal University, M anipal, Udupi, Karnataka - 576104. \\ E-mail : tessy.j@ manipal.edu
}

\begin{abstract}
Problem statement: "A study to assessthe effectiveness of academic stress management programme on academic stress and academic performance among higher secondary students in a selected school of Udupi district, Karnataka, India"

Objective : To evaluate the effectiveness of academic stress management programme on academic stress and academic performance.

Materials and Methods: Study was conducted among 96 subjects. Data were collected using Demographic Proforma and Academic stress Rating Scale. Academic performance was assessed by verifying existing school records of formative evaluation test conducted in the month of January and February 2013. Academic stress management programme was provided one hour per day for three consecutive days.
\end{abstract}

Result: Data were analysed using t test and Wilcoxon signed rank test. Result showed a significant difference in pretest post test stress level and academic performance.

Conclusion: The findings of the study indicated that academic stress management programme was effective in reducing academic stress but not in improving academic performance.

Keywords: academic stress, academic stress management programme, academic performance, higher secondary students

\section{Introduction}

Adolescence can be a stressful time for parents and adults who work with teens. Children are dealing with the challenges of going through puberty, meeting changing expectations and coping with new feelings. Many also worry about moving from a middle or junior high school to secondary school level. ${ }^{1}$ Adults always under estimate the level of stress on teens and young adults. Adolescents experience a spectrum of stress ranging from ordinary to

\begin{tabular}{|c|}
\hline Access this article online \\
\hline Quick Response Code \\
\hline
\end{tabular}

severe. Long term exposure to stress is associated with a variety of chronic psychological and physiological illness in addition to smoking, drug abuse and high risk sexual behaviour. $^{2}$
A cross sectional descriptive study was carried out by De Silva, Liyanage and Katulanda (2011) among 6000 grade 10 and 12 school children of Colombo District, selected by multi-staged Stratified random sampling, using Sheldon Cohen's self-administered "Global Measure of Perceived Stress scale(PSS) to assess the prevalence of stress among adolescent school children. Mean Perceived Stress Scale score was 15.29 ( $S D=5.34)$. When compared to a student in grade 10 (mean: 13.2), students following Advanced Level (AL) mathematics (mean: 15.19, $\mathrm{p} \varangle .001$ ) and biology (mean: 15.03, $p \varangle 0.001$ ) were less likely to have a higher stress score. Researcher found that students who had $\varangle 6$ marks for the previous term test had a higher stress when compared to students who had $>90$ marks. ${ }^{3}$

A cross-sectional study was conducted by Feld (2011) among three hundred eighty students in grades 9 through 12 from two colleges preparatory high schools of Wesleyan 
University, Middletown with a purpose to explore the effects and sources of stress in high-achieving environment. Tools used were students life satisfaction scale, school attitude assessment questionnaire revised, and questions about stress, health, coping, internal and external expectations, peers, support-seeking behaviour, and stress reduction. Eighty four percentage of students reported that their homework load had a major effect on increasing their stress level. Personal drive was also reported to have a high effect on stress level by $65.5 \%$ of students. College goals had a high effect on increasing stress level for $57.7 \%$ of students and expectations of their parents had a high effect on increasing their stress level for $51.1 \%$ of students. Students who experience more stress spend more time on their academic work $(r=0.294$, $\mathrm{p}<001)$. Additionally, students who spend more time on their work tend to have higher GPAs $(r=0.251, p<0.001)$. The importance of academic success to themselves is positively correlated with stress level $(r=0.195, p \varangle 0.01)$. More than $50 \%$ of students experiencing mood swings irritability, inability to initiate work and lack of concentration at least once in a week. More than $20 \%$ students experience inability to initiate work and lack of concentration and constant fatigue almost every day and $28 \%$ of students experience $5-10$ symptoms of stress per week. The study found a significant but weak association between stress and the prevalence of symptoms per week $(r=0.387, p<0.001){ }^{4}$

A study was conducted by Taragar (2008) in Dharwad taluk of Karnataka state to assess the stress among high school students and its relationship with demographic variables. A total of 538 students completed the stress scale prepared by the researcher. Among male students $66.00 \%, 25.50 \%$ and $8.50 \%$ of the students experienced stress, high stress and low stress respectively, among female students 71.70 $\%, 21.90 \%$ and $6.40 \%$ of the students experienced stress, low stress and high stress respectively. On the whole, 69.00 $\%, 15.60 \%$ and $15.40 \%$ of the students experienced stress, high stress and low stress respectively. The chi-square value 47.34 indicated that there was a significant association between gender and stress $(p=0.01)^{5}$
The Objective of the study was to evaluate the effectiveness of academic stress management programme on academic stress and academic performance.

\section{Materials and Methods}

Evaluative approach with quasi experimental design was considered for the study. The study was conducted among 96 higher secondary school students selected from selected pre university colleges of Udupi district. Private English medium schools following state syllabus and having monthly class test as a part of formative evaluation was included. Convenient sampling technique was adopted to select the samples. Formal administrative permission was taken from the Dean, M anipal College of nursing, $\mathrm{M}$ anipal. Institutional Ethics Committee (IEC) clearance and permission was obtained to conduct the study. Permission was also obtained from institutional research committee, MCON, Manipal. Written permission was taken from school authority. Purpose of the study was explained to the participants about the study and written consent was obtained from the subjects.

Demographic preforma was developed by the researcher to collect back ground information of the subjects selected for the study. Academic stress rating scale was developed by the researcher and it consists of 32 items. The items are expressed in the form of statements. Each item has 4 alternatives: strongly agree, agree, disagree and strongly disagree with the scoring of 1, 2, 3 and 4 respectively. Items are given under headings of examination stress, stress from peers, and stress from self, study habits and time management. The highest score was 128 and lowest score was 32. Academic stress were categorised as mild (32-64), moderate (65-90) and severe (91-128). Content validity of the demographic proforma and stress scale was ensured by giving to subject experts. The modifications made as per the experts suggestions are as follows. Reliability of the tool was established using Cronbach's alpha method and was established as 0.74 .

Demographic Proforma and Academic Stress Rating Scale were administered to the subjects on the first day of the data collection and academic stress management 
programme was conducted on three consecutive days. Intervention was provided two weeks before their examination. Average time taken to fill in the questionnaire was 15 minutes. After that one hour session was conducted. First session was on causes of stress among students, effects of stress on body and mind and time management. Students prepared time management plan for a week. Second day the session was on study habits. Third day dealt with examination preparation and demonstrated relaxation techniques such as meditation, deep breathing and JPM R. Post test was conducted 30 days after intervention, after participants' examination result published. For 48 subjects in the control group pre-test and post test only were conducted.

\section{Statistical methods}

Data were analysed using SPSS 16 version software. Data were analysed using descriptive and inferential statistics. Level of significance was 0.05 . Normality of the data was tested using Shapiro Wilk test. Paired t test was used for comparing the pre-test and post-test stress score of intervention group. Man Whitney $U$ test was used for comparing the post-test stress scores of intervention and control group as the data did not follow the normal distribution. Wilcoxon signed rank test was used for comparing the median pre-test and post-test academic score of intervention group as the data were not following normal distribution.

\section{Results}

\section{Description of sample characteristics}

Sample characteristics are given in table 1 .

\section{Description of stress}

Majority (80.2\%) of the students experienced moderate level of academic stress and only $6.2 \%$ students had severe academic stress. M oderate level of stress was experienced by $13.5 \%$ of the subjects. Majority (46.9\%) of them were having poor academic performance and $40.6 \%$ subjects had average level of academic performance.

Effectiveness of academic stress management programme on academic stress
Findings are presented in table 2 . Significant difference is found between mean pre-test and post-test stress scores as the $p$ value is 0.001 and $t$ value is 5.13 . Hence it is inferred that academic stress management programme is effective in reducing academic stress among higher secondary students. Significant difference is also found between posttest median stress scores of intervention and control group $(p=0.032)$.

\section{Effectiveness of academic stress management} programme on academic performance. Data in table 3 show that $p$ value is statistically significant 0.05 level $(p=$ 0.002). Man Whitney $U$ test was used for comparing the post-test academic scores of intervention and control group. Though there is increase in median scores, difference was not statistically significant $(p=0.631)$. Hence it is inferred that academic stress management programme was not effective in improving academic performance among higher secondary students.

\section{Acknowledgement}

Authors acknowledge all the experts who gave their valuable time and suggestions for validating the tools. We also express my thanks to all the school authorities where we have done this study. Our special thanks to all the participants of the study for their co-operation.

Table1. : Frequency and percentage of sample characteristics

\begin{tabular}{lcc}
\hline Sample Characteristics & Frequency & Percentage \\
\hline Gender & 22 & 45.8 \\
Male & 26 & 54.2 \\
Female & & \\
Education of Father & 1 & 2.1 \\
Illiterate & 18 & 37.5 \\
Upper primary & & \\
High School & 15 & 31.2 \\
PUC & 12 & 25 \\
Graduate Degree & 2 & 4.2 \\
Post Graduate Degree & & \\
Education of mother & 2 & 4.2 \\
Illiterate & 8 & 16.7 \\
Upper primary & 14 & 29.2 \\
High School & 14 & 29.2 \\
PUC & 9 & 18.8 \\
Graduate Degree & 1 & 2.1 \\
Post Graduate Degree & &
\end{tabular}




\begin{tabular}{lcc}
\hline Sample Characteristics & Frequency & Percentage \\
\hline Type of Family & 36 & 75 \\
Nuclear & 9 & 18.8 \\
Joint & 3 & 6.2 \\
Extended & 7 & \\
Number of siblings & 12 & 14.6 \\
Only Child & 13 & 25 \\
1 & 11 & 27.1 \\
2 & 5 & 22.9 \\
3 & & 10.4 \\
M ore than 3 & 30 & \\
Birth Order & 14 & 62.4 \\
1 & 2 & 29.2 \\
2 & 2 & 4.2 \\
3 & & 4.2 \\
4 & 3 & \\
Family income & 10 & 6.2 \\
¿000 & 29 & 20.8 \\
5001-10000 & 60.4 \\
10001-20000 & & 12.5 \\
$>$ 20000 & 14 & \\
Occupation of father & 12 & 29.2 \\
Unemployed & 4 & 25 \\
Self employed & 12 & 8.3 \\
Unskilled & 6 & 25 \\
Non professional & & 12.5 \\
Professional & 41 & 85.4 \\
Occupation of mother & 7 & 14.6 \\
Housewife & & \\
Working & & \\
\hline & & \\
\hline
\end{tabular}

Table 2 : M ean, Standard deviation, Standard error and $p$ value of pre-test and post-test stress level of intervention group.

\begin{tabular}{lccccc}
\hline Stress & mean & $\begin{array}{c}\text { Std. } \\
\text { deviation }\end{array}$ & Std. error & t - value & p-value \\
\hline Pre test & 78.5 & 10.69 & 1.54 & 5.14 & 0.001 \\
Post test & 75.20 & 9.18 & 1.32 & & \\
\hline
\end{tabular}

\section{Discussion}

The present study concluded that academic stress management programme was effective in reducing academic stress $(t=5.13$, $p=0.001)$ and not in improving academic performance $(t=0.480$, $p=0.631$ ) Similar findings were reported in the study conducted

\section{References}

1. Denise E, Judith W, Herrman. Adolescent stresses through the eyes of high-Risk teens. Paediatric nursing 2008; 34(5): 375-380.

2. Aggarwal S, Prabhu H R A, Anand A, Kotwal A. Stressful life events among adolescents: The development of a new measure. Indian journal of psychiatry 2007;49(2):96-102.

3. De Silva, M. K., Liyanage, I.K., Katulanda,P (2011). Prevalence of Perceived Stress among Adolescent School Children in Colombo District [internet]. [updated 2012 may18].

4. Feld, D. L (2011). Student stress in high-pressure college preparatory schools. [BA]. Middletown: Wesleyan University.
Table 3 : M edian, Inter quartile range, $z$ value and $p$ value of pretest and post-test academic score of subjects.

\begin{tabular}{lcccc}
\hline Academic score & mean & Inter quartile & $\begin{array}{c}\text { Z value } \\
\text { range }\end{array}$ & p-value \\
\hline Pre test & 334 & $277-416$ & 3.08 & 0.002 \\
Post test & 342 & $290-419$ & & \\
\hline
\end{tabular}

by Vliet and Andrews (2009) to find the effectiveness of Internet-based course for the management of stress for junior high schools. Its findings revealed significant increases in knowledge $[F(2,159)=9.735, p B 0.001, E S=0.36]$ and support seeking coping $[F(2,159)=9.921, p B 001, E S=0.015]$ and significant decreases in stress, avoidant coping $[F(2,159)=3.331, p=0.037, E S=0.22]$ and the total difficulties over time $[F(2,159)=3.298, p=0.038 \text {, } E S=0.16]^{6}$. Present study findings are also in harmony with the findings of the study conducted by Tenenbaum (2012) among 17 school children from a private school in Atlanta to find out the effectiveness of a school based intervention on test anxiety. Self-reported anxiety collected before and after intervention and data analysed using paired t test. Result demonstrated significant reductions in anxiety disorders for the participants involved (MD: 3.63, $t=2.31, p=.036$ ). ${ }^{7} A$ meta-analysis done by Kraag, Zeegers, Kok, Hosman and Saad (2006) also supported the findings of present. They evaluated the effect of school programs targeting stress management or coping skills in school children. Overall effect size for the programs was - 1.51 . Effect was calculated per intervention type, and positive effects were found for stress symptoms with a pooled effect size of 0.865 (95\% Cl: - 1.229, - 0.502) and for coping with a pooled effect size of $-3.493(95 \% \mathrm{Cl}:-6.711,-0.275){ }^{8}$

\section{Conclusion}

The findings of the study indicated that academic stress management programme was effective in reducing academic stress but not effective in improving academic performance. It is concluded that there could be various other factors influencing academic performance of higher secondary students.

5. Taragar, S. (2009). Stressors among the students of high school [M Sc] Dharwad: University of agricultural sciences.

6. Vliet, H. V., \& Andrews, G. (2009). Internet-based course for the management of stress for junior high schools. Australian and New Zealand Journal of Psychiatry. 43:305-309.

7. Tenenbaum, L. S. (2012). A school-based intervention for third grade students experiencing test anxiety $[\mathrm{PhD}]$. College of education: Georgia State University.

8. 8. Kraag G,Zeegers M P, Kok G, Hosman C,Abu saad H H. School programs targeting stress management in children and adolescents: $\mathrm{A}$ meta-analysis. Journel of school psychology. 2006: 44(6); 449-472. 